\title{
Impacts of Climate Change and Remote Sensing Technology in its Mitigation Options through Forest Management
}

\author{
Rabindra Man Tamrakar \\ Chief Survey Officer \\ Survey Department
}

\author{
Keywords \\ Green House Gases (GHG), Emission, Climate Change, \\ Remote Sensing, LiDAR
}

\begin{abstract}
Greenhouse effect causes global warming and its main consequence is the climate change. Average global temperature is rising significantly over the period. Despite the contribution of total GHG emission by Nepal to the global community is insignificant compared to the developed countries, Nepal has already encountered several adverse effects due to the global climate change, leading to the melting of Himalayan glaciers, reduced agriculture production, loss of biodiversity and ecosystems and changes in social structure and livelihoods. Forest land use change is responsible for $\mathrm{CO}_{2}$ emissions. Forest management therefore can play a significant role in climatic change mitigation. REDD has become the key mechanism in mitigating climate change. The success of REDD mechanism however depends primarily on availability of reliable forestry data including biomass changes and forest carbon estimates. Various Remote Sensing data including optical sensor data have been used for the analysis of forest cover change and estimation of degree of deforestation and degradation. LiDAR however has been widely used in estimating forest biomass for the climate change mitigation.
\end{abstract}

\section{Introduction}

The atmosphere is largely transparent to incoming shortwave (or ultraviolet) solar radiation, which is absorbed by the Earth's surface. Much of this radiation is then reemitted as heat energy at long-wave, infrared wavelengths. Some of this energy escapes back into the space, but due to the increasing presence of Greenhouse Gases (GHG - i.e. Carbon Dioxide, Methane, Nitrous Oxides, Ozone and Chloro-fluoro Carbons) in the earth's atmosphere, heat energy then is trapped inside. The effect of this heat trapping due to the increasing presence of Greenhouse Gases in the atmosphere is known as greenhouse effect. This greenhouse effect causes global warming and its main consequence is the climate change.

According to the statistics, Nepal's per capita emission ranks lowest among SAARC nations at 0.11 metric tones per year. Even though Nepal contributes very low emissions it is highly vulnerable to the effects of climate change. Increase in mountain snow melt and an outburst from glacial lakes could lead to flooding with a devastating impact on the life of poor people living in both mountain and plain areas. Climate change has therefore become a priority issue in Nepal. In addition, there is a strong relationship between economic development and climate change. In order to increase the economy, the country must reduce its emissions.

Forestry sector has recently become one of the high-profile sectors in the debate on reducing emissions in developing countries. Forest land use change is responsible for $\mathrm{CO}_{2}$ emissions. Forest management therefore can play a significant role in climatic change mitigation. Forests can be a sink or source of carbon, depending on the management regimes that are implemented. Forest cover can sequester carbon through photosynthetic processes.

REDD (Reducing Emission from Deforestation and Forest Degradation) has become the key mechanism in mitigating climate change, especially in the developing countries such as Nepal. The success of REDD mechanism however depends primarily on availability of reliable forestry data including forest carbon estimates, forest cover and biomass changes in different scales, extent and time periods. Various Remote Sensing (RS) data generated from optical sensor systems and active microware systems such as RADAR (Radio Detection and Ranging) along with GIS technology have been used for the analysis of forest cover change and estimation of degree of deforestation and degradation over the period. LiDAR (Light Detection And Ranging), one of the active RS systems, however, has been widely used in estimating forest biomass for the climate change mitigation. 


\section{Trend of Emission and Global Temperature} Carbon Dioxide $\left(\mathrm{CO}_{2}\right)$ is the major component which forms more than 80 percent of the total GHG. $\mathrm{CO}_{2}$ is mainly produced from burning of fossil fuels such as oil, coal and gases. Studies reveal that rapid industrialization coupled with urbanization, excessive consumption of fossil fuels, deforestations, slash \& burning of forests, agricultural development etc. in the world over the past two centuries have resulted in significant increase of $\mathrm{CO}_{2}$ gas in the atmosphere. Before the rapid industrialization, the share of $\mathrm{CO}_{2}$ gas in the atmosphere was estimated to be $280 \mathrm{ppm}$ (parts per million) which now has increased to $390 \mathrm{ppm}$. If this trend in rising of $\mathrm{CO}_{2}$ gas continues, the level of this gas in the atmosphere is predicted to be 800 ppm at the end of this century, which will create serious impacts on the entire earth. Concentrations of other GHG gases such as methane and nitrous oxide as well have significantly increased over the period.

Over the last few decades, studies have indicated that temperature of earth surface has been rising and this has caused changes in weather patterns, resulting in rise in sea level, melting of glaciers, floods, draught, loss in agricultural production etc. Meteorological measurement records show that a warming of 0.3-0.6 degrees Celsius in global average temperature since 1860 . Moreover, the global temperature has increased by 0.74 degrees Celsius during the period of 1906 to 2005. It is also recorded that 1990s was the warmest decade of the global surface temperature since 1850 . The studies further reveal that the global temperature will rise between $1.5^{\circ}$ to $4.5^{\circ}$ Celsius by sometime in the 21st Century. In addition, it has been suggested that warming of more than $2.5^{\circ} \mathrm{C}$ could reduce global food supplies and contribute to higher food prices (UNEP \& UNFCCC, 2002).

\section{Effects of Climate Change in Nepal}

Despite, the contribution of total GHG emission by Nepal to the global community is insignificant (nearly $0.025 \%$ of the total global emission) compared to the developed countries such as the United States, Russia, Australia, and European communities, Nepal has already encountered several negative effects due to the global climate change. According to the National Communication Report prepared by the Government of Nepal, net emission of $\mathrm{CO}_{2}$ was about 9.7 tons and the net emission of methane was estimated to be 0.95 tons in 1994. Studies carried out by the Department of Hydrology and Meteorology, Government of Nepal reveal that average temperature in Nepal is increasing at the rate of nearly 0.06 degrees Celsius per year between the period of 1977 and 1994. Another temperature analysis from 1976 to 2005 has revealed that the average temperature in Nepal has increased by 0.597 degrees Celsius per year. The projected figures for Nepal further show that average increase in temperatures of $1.2^{\circ} \mathrm{C}$ for the year $2030,1.7^{\circ} \mathrm{C}$ for 2050 and $3.0^{\circ} \mathrm{C}$ for 2100 . The temperature in the Himalayan Region, on the other hand is increasing at a greater rate, which is having severe effects on the glacial lakes, which are the main source of Nepal's water resources. For example, the Rika Samba Himalayan Glacier in the Dhaulagiri region western part of Nepal is receding at a rate of $10 \mathrm{~m}$ per year.

People's lives and livelihoods, especially of poor and marginalized social groups such as farmers, indigenous communities, women and children in the rural areas who are least able to cope with are most at risks and vulnerable to the disasters caused by the climate change. The study shows that Nepal is ranked fourth vulnerable country among the 170 countries from the impacts of climate change.

Several effects of climate change in Nepal have been recorded. One of the major issues is the melting of Himalayan glaciers in Nepal. International agencies such as UNEP has warned that more than 40 Himalayan glacial lakes of the country are dangerously close to bursting because of the ice melt caused by global warming. Melting of glaciers in the Himalayas will cause in seasonal variation in river flows, which will subsequently result in more floods and draughts in the country. In addition, this will effect on irrigation and drinking water supply as well as reliability of hydroelectricity. Moreover, rapid melting of glaciers even may result in Glacier Lake Outburst Floods (GLOF), which can be catastrophic to communities and infrastructure along the riversides.

Other impacts of climate change are the reduced agriculture production, loss of biodiversity, increased desertification and changes in social structure. Nepalese economy depends primarily on agriculture, contributing about 32.7 percent of GDP and employing more than 65.7 percent of the total population. Agriculture land is therefore very important to Nepalese people as it provides food, shelter, clothing and energy required for the people. Without the proper management of land, it is not possible to improve the economy of a country. Latest figures of Ministry of Agriculture and Cooperatives, Government of Nepal indicate that the country has nearly 3.1 million hectares of cultivated land, producing 8.1 million of food grains. Studies have shown that both arable land and agricultural production in Nepal have been decreasing due to the draught, floods, loss of top fertile soil, landslides etc. resulted from the impacts of climate change. In addition, arable lands primarily depend on the natural rainfall (monsoon) water for irrigation. Rainfall patterns on the other hand will be erratic due to the effects of the climate change causing to food insecurity and threat to Nepalese economy. If these trends of effects continue, Nepal will face serious food crisis in the coming years. 
Another adverse effect of climate change can be noticed in the country's ecosystems, resulting in the loss of biodiversity. Although Nepal is small in size, nearly 0.09 percent of the earth surface, its contribution in biodiversity conservation is of global significance. High topographic variations along the north-south transect offers higher level of diversity at species, ecosystem and genetic level. It is estimated that about 118 different ecosystem types are found in this country where more than 15,000 plant species exists in the wild. In addition, more than 700 species of the total identified plant species are found to be of medicinal importance. Impacts of climate change will slowly alter the existing ecosystems resulting in the extinct of valuable plant species in the future.

Likewise, negative effects of climate change can also be noticed in livestock production. Major concerned in livestock production are the feed, reproduction, livestock health and management. As described above, climate change can cause the draught, floods and loss in agricultural production, which in turn can reduce the required amount of animal fodders such as palatable grasses and feeds from agricultural products. This will lead to the poor animal health and reproduction capacity.

Finally, human health as well can be seriously affected by the climate change in Nepal although it is difficult to perceive the impacts. The growing risk of Malaria, Kalazar and Japanese Encephalitis is considered as the potential impacts of climate change on human health as warmer temperature may create favorable conditions for more vectors and germs spread such as mosquitoes. Specifically, subtropical and warm temperate regions of Nepal would be more vulnerable due to Malaria, Japanese Encephalitis and Kalazar. Moreover, with the warming of higher altitudes, it has been predicted that there may be an increased spread of lower altitude disease vectors such as mosquitoes and consequent spread of these diseases.

\section{Forest Degradation and Emissions}

Forest degradation and deforestation is reported to contribute more than 17 percent of global GHG emissions, most of which come from developing countries. Nepal is a land locked country located between China in the north and India in the south covering $147,181 \mathrm{~km}^{2}$ surface areas. The current forest cover in the country is 5.8 million ha. The country can be divided into five major physiographical regions-Terai, Siwaliks, Middle Mountains, High Mountains and the Himalayas. Out of the total area about 39.6 percent area is officially declared as forests, including the areas under shrublands, which include shrubs as well as trees of less than $10 \%$ crown coverage occupy almost $10.6 \%$ of the total country area.

Studies on carbon estimation from different physiographical regions of the country reveal that a substantial amount of carbon stocks has been currently hold in the forests. If these forests could be managed properly, additional $\mathrm{CO}_{2}$ gas can be captured and stored in the forests. However, increasing demands of forest products and services have exerted tremendous pressure on the forest resources. The studies show that the forest cover in Nepal which was about 60 percent in 1950's has reduced to 39.6 percent in 1990's. Most of the deforestation and degradation of forests has occurred in the Terai region, the southern portion of the country lying with the Indian border. Studies have further shown that Nepal has lost nearly 570,000 hectares of natural forests in 27 years between 1964 and 1991, most of which were converted into the agricultural land. Moreover, the studies reveal that the overall deforestation rate in Nepal is currently $1.7 \%$, which is well above the Asian average (1\%) and the global average (1.3\%).

There are several factors attributable to the depletion of forest coverage in Nepal. The most common factors that affect forestry land use change in Nepal include:

- Demographic variables such as population pressure and its growth rate

- Rural/urban distribution

- Higher dependence on forest resources

- Poverty

- $\quad$ Shifting cultivations

- Migrations of people from hills to the forested plain areas.

- $\quad$ Forest Encroachments

- Uncontrolled grazing on the forested lands

- Smuggling of timber, fuelwood and fodders

- Resettlement Programmes in the Terai Region

- Use of fuelwood for cooking and heating

\section{Mitigation Options through Forest Management} Reduced Emissions from Deforestation and Degradation (REDD) is assumed to be the cheapest means of mitigating carbon emission in the world. Thus, conserving and enhancing forests in the country might result in the reduction of the emissions as well as in the enhancement of the country's economy.

In December 2007, the $13^{\text {th }}$ Conference of Parties (COP) of United Nations Framework Convention on Climate Change (UNFCCC) has approved REDD as the key policy instrument in mitigating climate change. The REDD device will be applicable specifically to the developing countries like Nepal as the policy will be able to provide incentives to reducing emissions from deforestation and forest degradation. The World Bank (WB) has established Forest Carbon Partnership Facility (FCPF) to support developing countries in their efforts to build capacity for 
REDD at the country level. The purpose of the facility is to assist developing countries to be ready for REDD by 2012.

\section{Remote Sensing Data for Forest Management}

Airborne and spaceborne Remote Sensing (RS) data generated from various optical sensor systems and active microware systems such as RADAR along with GIS technology have been widely used for the preparation of forest inventory and analytical study of forest cover change over the period as well as for estimation of degree of deforestation and degradation. LiDAR data, however, have been extensively used in estimating forest biomass for the climate change mitigation in many parts of the world. It is simply because of the fact that the LiDAR systems are cost-effective, versatile, operationally flexible and robust sampling tools for forest management (Lim, et al, 2010).

Airborne RS data such as aerial photography were initially used for forest mapping and preparation of forest inventory before the availability of commercial satellite images. In Nepal for the last few decades, remote sensing techniques specifically aerial photogrammetry was extensively used in the forestry sector. First systematic Forest Research Survey was conducted in the period of 1963-67 using black and white aerial photographs taken in 1963/64. This Research Survey however was limited to the Terai and Hill regions of the country, generating data/inventory mainly of commercial forests.

In 1986, Land Resources Mapping Project (LRMP, 1986) has prepared Land Utilization maps at 1:50,000 scale of the entire Nepal, using 1978/79 aerial photographs with extensive ground verifications. These data have provided an opportunity to estimate forest biomass and prepare basic forest inventory of the country. LRMP data has also placed specific emphasis on forests, shrublands, agriculture, and grassland resources. Forest units have been further classified into various components including forest cover types, species associations, crown density coverage, and maturity classes. LRMP information as well was used for the preparation for the Master Plan of the Forestry Sector of Nepal in 1989.

Although National Remote Sensing Centre under the Ministry of Forest and Soil Conversation was established in the early 1980s in order to develop the forest inventory of the nation, National Forest Inventory was only prepared in the year of 1994 using remote sensing data such as 1990 Landsat images and available aerial photographs with the field measurements collected during the period of 19901999.

Likewise, in 2000 forest cover mapping of the entire Nepal was carried out using the Indian Remote Sensing
(IRS) data of the year 1999/2000 in collaboration of Japan Forest Technical Association Information System Development Project.

Moreover, Survey Department, Government of Nepal, has prepared Topographic maps of the entire nation in 2001. One of the major components of these maps is the land cover information which is very useful for the estimation of forest biomass for the climate change study. Topographic maps at the scale of $1: 25,000$ were prepared for the Terai and the Mid Hill Regions of Nepal and are based on aerial photographs taken in 1992 and 1996 with extensive ground truthings. Topographical maps at the scale of $1: 50,000$ dated 1996-97 on the other hand are available for High Mountain and Himalayan Regions of Nepal. Moreover, digital data of these topographic map series are as well available from this department. These databases were created in 2002 using ARC/INFO GIS software programmes by a project under the Survey Department with the financial assistance from the Finish Government. These databases are valuable tools for the preparation of national forest inventory as well as for the estimation of forest biomass using GIS technology.

In 2009, the global forest mapping was completed by FAO Global Land Cover Network using 2000 Landsat images. One of the major objectives of mapping was to acquire the information on the forest cover extent.

In 2010, Forest Resource Assessment (FRA) Nepal project has started to provide National Forest Inventory of Nepal, in collaboration with Government of Finland for a period of five years (2010-2014). This project is conducted under the Ministry of Forests and Soil Conservation (MFSC) and the Department of Forest Research and Survey is the implementing agency. Major objectives of this project is to generate national level baseline data of status of present forest cover, growing stock, wood and non-wood products, forests in the protected areas, tree resources outside the forest, biological diversity, biomass above the ground and soil carbon. High resolution satellite images (up to 0.5 $\mathrm{m}$. resolution) along with LiDAR technology are used to obtain the information. This project will provide necessary forest resource databases for REDD programmes using high resolution satellite images. Moreover, since LiDAR technology is being used, the project as well will be providing three-dimensional information regarding forest structures that are required for biomass calculations for the climate change mitigation study.

Although LiDAR technology was introduced in Nepal only in 2010 for obtaining information on forest structure, its application specifically for estimation of forest canopy height and biomass estimation is extensively used long before in many parts of the world. One of the main reasons of using this technology is its capabilities of recording the time-varying return signals that provide tree structural 
information including tree heights and ground surface height (Zang, et al, 2008). It is because LiDAR can penetrate through the top layer of forest canopy, providing the information on the under storey layers. Studies also have shown that direct estimates of crown height from LiDAR technology to be as accurate as the field data measurement. Moreover, LiDAR data resolve the major problems associated with optical data that is incapable of distinguishing over storey from the under storey vegetation cover. This then lead to confusion between layers, resulting in the overestimation of crown coverage (Tickle, et al, 2001). Another advantage of using LiDAR technology is that its systems are based on active remote systems which simply use pulses of laser light. This then provides opportunity to capture biophysical data even at night.

Despite LiDAR data have significant advantages over the optical data, especially for the estimation of forest structure and biomass, further research works on LiDAR intensity and impacts caused by sensor angle, surface roughness or type, or atmospheric conditions need to be carried out.

\section{Conclusions}

Greenhouse effect causes global warming and its main consequence is the climate change. Despite, the contribution of total GHG emission by Nepal to the global community is insignificant compared to the developed countries, Nepal has already encountered several negative effects due to the global climate change, leading to the melting of Himalayan glaciers, reduced agriculture production, loss of biodiversity and ecosystems, increased desertification, floods, livestock production and changes in social structure and livelihoods. Forest degradation and deforestation have contributed significant amount of global GHG emissions. There is a high risk of releasing $\mathrm{CO}_{2}$ gas, originally stored in forest biomass, from the forests into the environment due to forest degradation and deforestation. If necessary measures are not taken to protect these forests then it would have serious impacts on the entire livelihoods of all communities of the nation. Therefore, role of forests which plays both as a source and sinks is crucial in the overall global climate change. Sustainable forest management is obligatory in order to mitigate the impacts of climate change in Nepal. UNFCCC has approved REDD as the key policy instrument in mitigating climate change and it will be applicable specifically to the developing countries like Nepal. Remote Sensing data including LiDAR data are useful for the preparation of forest inventory as well as for the estimation of forest biomass which are essential for implementating and monitoring of REDD programmes for climate change mitigation in Nepal.

\section{References:}

1. Clean Energy Nepal, 2002. Clean Energy Nepal's Fact Sheet \#2. Kathmandu, Nepal.

2. Dahal, N. 2006. Implications of Climate Change in Nepal: Some Observations and Opportunities. Paper Presented at 23rd Warden Seminar, November 2006 held in Pokhara, Nepal.

3. Department of Hydrology and Meteorology, 2007. Climatological \& Agrometereological Records of Nepal 2007, Department of Hydrology and Meteorology, Ministry of Environment, Science and Technology, government of Nepal.

4. DFRS, 1999. Forest Resources of Nepal (1987-1998). Department of Forest Research and Survey, Ministry of Forest and Soil Conservation, Kathmandu, Nepal.

5. DFRS, 2009. BankoJankari, Vol.19, No.2. Department of Forest Research and Survey, Ministry of Soil and Conversation, Government of Nepal.

6. DFRS, 2010. ForestResourceAssessment (FRA) Nepal Project, Department of Forest Research and Survey, Ministry of Soil and Conversation, Government of Nepal.

7. FAO, 2006. Global Forest Resources Assessment 2005. Progress towards Sustainable Forest Management; FAO Forestry Paper 147: Food and Agriculture Organization of the United Nations, Rome, Italy.

8. Jackson, W.J., R.M. Tamrakar, S. Hunt, K.R. Shepherd, 1998. "Land Use Changes in Two Middle Hills District of Nepal" in Mountain Research and Development [1998:18 (3):193-212].

9. Kanel, K. R. et al. 2009. Assessment of Land Use, Forest Policy and Governance. A report submitted to REDD-Forestry and Climate Change Cell, MFSC by NFA, Kathmandu, Nepal.

10. Karim, Z, R.M. Tamrakar, 1993. "Application of GIS for Shivapuri Watershed Project" in Remote Sensing Applications to the Planning and Management of Environment, Natural Resources and Physical Infrastructure. UNSAP/CDG/eas/ICIMOD, Kathmandu, Nepal.

11. Kienholz, H., H. Halfner, G. Schneider and R.M. Tamrakar, 1983. "Mountain Hazard Mapping in Nepal's Middle Mountains" in Mountain Research and Development [1983:3(3):195-220].

12. Lefsky, M. A., W.B. Cohen, G.G. Parker and D.J. Harding. 2002. Lidar Remote Sensing for Ecosystem Studies, Bioscience Vol.52, No.1 19-30. 
13. Lim, S, J.C. Trinder, R. Turner, 2010. Full Waveform Lidar Remote Sensing for Forest Inventory in New South Wales, Australia. School of Surveying and Spatial Information Systems, UNSW, Sydney, NSW 2052, Australia.

14. LRMP, 1986. Land Resources Mapping Project, Economic Report, Government of Nepal \& Government of Canada. 55 pp.

15. Malla, G., 2008. Climate Change and its impact on Nepalese Agriculture. The Journal of Agriculture and Environment. Vol 9. Kathmandu, Nepal.

16. MFSC, 2008. Forest Carbon Partnership Facility Readiness Plan Idea Note (R-PIN) Nepal.

17. Ministry of Forest and Soil Conservation, 1988. Master Plan for Forestry Sector, Nepal. Ministry of Forest and Soil Conservation, Kathmandu.

18. MoEST and UNDP, 2008. National Adaptation of Programme of Action to Climate

19. Change Project Document. Ministry of Environment, Science and Technology \& United National Development Program.

20. Pandey, B. R. 2002. Potential of Using Clean Energy in Transport Sector, Paper presented at Seminar on Air Quality Management of Kathmandu Valley: Challenges \& Opportunities, Ministry of Population and Environment, Kathmandu, Nepal.

21. Pokhrel, A. P., 2002. Temperature and Precipitation Trend and Its Impact in Nepal, Paper presented on First Preparatory meeting on Eighth Conference of Parties, COP 8, organized by IUCN Nepal.

22. Regmi, B. R and A. Adhikari. 2007. Climate Risk and Vulnerability in Nepal. Country Case Study. Human Development Report 2007/2008 Fighting Climate Change: Human Solidarity in a divided world. Human Development Report Office Occasional Paper, UNDP.

23. Shrestha, A.M, 2010. "Preparing for climate change: an evaluative framework for prioritizing adaptation measures in Nepal," in Botanica Orientalis - Journal of Plant Science (2010) 7: 35-42.

24. Tamrakar, R.M., 2000. "Management Options for Environmental Protection in Nepal" in Environmental Special Issue 2000. Gurans Nepal, Kathmandu, Nepal.

25. Tamrakar, R.M., 1999. "Environmental Imbalance is Increasing Specially in the Middle Mountains and Terai Regions" in Environmental Special Issue.
Society of Environment Journalist - Nepal (SEJNepal), Kathmandu, Nepal.

26. Tickle, P.K., C. Witte, A. Lee, R.M. Lucas, K. Jones and J. Austin, 2002. Use of Airborne Scanning Lidar and Large Scale Photography within a Strategic Forest Inventory and Monitoring Framework. Bureau of Rural Sciences and Cooperative Research Centre for Greenhouse Accounting, Kingston, Australia.

27. UNEP \& UNFCCC, 2002. Climate Change Information Kit.Sheet10.United NationEnvironmentProgramme and United Nation Framework Convention on Climate Change. WFP, 2009.

28. UNFCCC, 2002. Annotated Guidelines for the Preparation of National Adaptation Programmes of Action. Least Developed Countries Expert Group.

29. WFP, 2009. The Cost of Coping. A collision of crises and the impact of Sustained Food Security Deterioration in Nepal. United Nations World Food Progarmme. Nepal Food Security Monitoring System.

30. Wigley, T.M.L. and S.C.B. Raper. 1993. "Future Changes in Global-Mean Temperature and Sea Level," in Climate and Sea Level Change: Observations, Projections and Implications, R.A. Warrick, E. Barrow, and T.M.L. Wigley (eds.), pp.111-133. Cambridge University Press, Cambridge, 424pp.

31. Zhang, Z., W. Ni , A. Fu , Z. Guo, Guoqing Sun, and D. Wang , 2008. "Estimation of Forest Structural Parameters from LiDAR and SAR data," in The International Archives of the Photogrammetry, Remote Sensing and Spatial Information Sciences. Vol. XXXVII. Part B8. Beijing 2008. 